\title{
A Hybrid Neutrosophic GIS-MCDM Method Using a Weighted Combination Approach for Selecting Wind Energy Power Plant Locations: A Case Study of Sinai Peninsula, Egypt
}

\author{
Amany Mohamed Elhosiny ${ }^{1}$, Haitham El-Ghareeb ${ }^{2}$, Bahaa T. Shabana ${ }^{3}$, and \\ Ahmed AbouElfetouh ${ }^{2}$ \\ ${ }^{1}$ Information system Department, Sadat Academy for Management Sciences, Tanta, Egypt \\ ${ }^{2}$ Information system Department, Faculty of Computer \& Information Sciences, Mansoura, Egypt \\ ${ }^{3}$ Computer science Department, Misr Higher Institute of Commerce and Computers (MET), Mansoura, \\ Egypt
}

\section{]jfis}

\begin{abstract}
The production and use of wind energy has eased the problems of energy scarcity and environmental pollution. However, the selection of locations for wind power plants is challenging because the associated decision-making process requires political, socio-economic, and environmental considerations. The selection of suboptimal sites has created several negative impacts. This study aims to resolve this issue by implementing the following factors: integrating a qualitative and quantitative multi-criteria decision-making framework for selecting locations for wind power plants; applying the new framework in Sinai Peninsula in Egypt, and investigating the neutrosophic analytic network process for weight assignment through expert-based and entropy-based criteria; choosing four potential alternative wind power plant sites, and using PROMETHEE-TOPSIS to help decision makers find the best possible alternative; and establishing the supremacy of one option over the other. The results indicate that by applying the proposed approach, an appropriate wind power plant location can be successfully selected among various alternatives.
\end{abstract}

Keywords: Single value neutrosophic numbers, Analytic network process, PROMETHEE, TOPSIS, Wind farms site selection, Multi criteria decision-making

Received: Oct. 30, 2020

Revised : Dec, 29, 2020

Accepted: Jan. 12, 2021

Correspondence to: Amany Mohamed Elhosin (amanyelhosiny2020@gmail.com)

(CThe Korean Institute of Intelligent Systems

cCThis is an Open Access article distributed under the terms of the Creative Commons Attribution Non-Commercial License (http://creativecommons.org/licenses/ by-nc/3.0// which permits unrestricted noncommercial use, distribution, and reproduction in any medium, provided the original work is properly cited.

\section{Introduction}

Burning fossil fuels are a major source of carbon dioxide $\left(\mathrm{CO}_{2}\right)$ and other greenhouse gas emissions, which contribute to global warming. According to the International Energy Agency (IEA), the global emissions of carbon dioxide from fuel combustion rose by 108\% from 1973 to 2015 [1]. There is increasing international interest in renewable energy sources, including wind energy, as excessive consumption of fossil energy sources (coal, oil, and natural gas) exacerbates environmental pollution, leading to global warming and damage to the ozone layer. The national energy strategy of Egypt planned to achieve approximately $20 \%$ of the total energy production from renewable energy sources by 2020. Presently, wind energy contributes 
approximately $12 \%$ of the total energy production. Besides multiple contributions of wind energy in various applications, wind-power generates the most significant amount of electricity amongst all renewable sources of energy. Preliminary studies and measurements have shown that Egypt has a rich source of wind energy in several regions, particularly in the region around the Gulf of Suez, which is considered one of the best regions in the world to produce electricity using wind power.

The selection of an appropriate location for the installation of a wind farm is problematic, and usually requires the application of operational research (OR), which is a combination of mathematical and computational techniques to select the best element from a set of available alternatives. The problem of selecting a site for wind farm construction is governed by the following three elements:

1. The objective behind selection of a particular site.

2. Constraints that define the necessary conditions to be met for an acceptable solution to the problem [2, 3].

3. Decision variables, which are numerical quantities whose values are chosen based on improvement of knowledge [2].

Selecting an appropriate location for the construction of a wing farm is the first obstacle faced by engineers while designing and developing a wind turbine. Geographic Information System (GIS), an information technology-based system with a variety of functions and toolboxes for the collection, processing, and visualization of spatial information, represents a typical decision-support system that involves the troubleshooting of spatially referenced data. The usage of GIS is crucial for site selection and generation of location-allocation models because it provides assistance in locating a set of candidate sites, and generates graphic output with appropriate solution visualization schemes [4, 5].

However, the uncertainty, ambiguity, and difficulty associated with the physical nature of the problem of site selection requires several decision-making approaches. Using the multicriteria decision-making (MCDM) method, we can determine the best alternative locations for installing wind farms based on a range of factors. This paper investigates the integration of the MCDM approach with GIS techniques to reinforce the analytical powers of the two methods [6]. The rest of the paper is organized as follows: Section 2 briefly reviews the literature; Section 3 recalls some basic concepts of single-value neutrosophic numbers, analytic network process (ANP), and the entropy-PROMETHEE-TOPSIS MCDM method. Section 4 explains the methodology of the proposed model, and the protocol to assist the decision-makers in evaluating the factors that influence the site selection for wind farm installation. In addition, a case study involving site selection for a wind farm in the Sinai Peninsular region of Egypt, has been also discussed. Finally, Section 5 presents the conclusions of this study and discusses the future direction of this research.

\section{Literature Review}

The selection of a location is a MCDM issue that requires a suitable process. Considering the multiple conflicting standards, MCDM methods can be applied to resolve site selection issues. MCDM techniques have adequately addressed problems associated with site selection for airport construction and infrastructure services.

The key role of the MCDM approach is to help decision makers (DMs) create a clear picture of complex decision-making issues, such as issues that combine financial and non-financial factors [3-9]. It also facilitates the evaluation of the dilemma in decision-making by splitting the original problem into several achievable aspects [7, 8]. MCDM assists DMs in solving problems using multiple conflicting standards that needs to be assessed. MCDM is a GIS-based tool that conducts decisionmaking to aid site-selection, and provide assessment for the adequacy of land use and resource utilization [10,11]. MCDM is an efficient and realistic approach capable of conducting quantitative analysis in scientific ways, even under uncertain or ambiguous environment.

The combination of GIS and MCDM techniques have been applied to a variety of issues associated with spatial resolution and energy planning, including waste management [12, 13], hydrology, water resources management [14], urban and regional planning [15], power generation sites [16], and planning of biogas facilities [17]. Several researchers have examined the nature of wind-power with the aim of identifying and evaluating the most suitable location for a wind farm. Using GIS software and MCDA approaches, researchers have evaluated certain criteria, which were projected to relevant cartographical form. More specifically, linear weight measurement was used as the MCDM method for locating appropriate sites for the installation of wind farms in the United Kingdom [18]. The GIS-based MCDM method was used in the analytical hierarchy process (AHP) for the selection of large-scale wind turbines in Thailand by Bennui et al. [19]. Tegou et al. [20] conducted a study to determine the best areas for wind power generation in Lesvos, Greece using a GIS program with an AHP approach.

Atici et al. [21] implemented the GIS-MCDM methodol- 
ogy in two regions, Belikisr and Canakkale, in Turkey, to locate suitable sites for wind power development. The methodology involves the application of three MCDM techniques: ELECTREEIII, ELECTRE-TRI, and stochastic multi-objective acceptability analysis. Solangi et al. [22] used a methodology based on integrated Delphi-AHP and fuzzy technique for the order of preference by similarity to ideal solution (F-TOPSIS) to rank and select renewable energy resources in Pakistan.

Since each method has its own characteristic properties, fulfilling all requisite standards is very complex, which is an inherent flaw of any decision-making process. There are no suitable strategies of MCDM that perfectly fit into any particular problem. Therefore, understanding the nature of a problem is a key step in determining the optimal solution for it [9-23]. Traditional MCDM approaches presume that accessible and reliable information is required to evaluate the decision problem. However, the available information is subject to doubt, inaccuracy, and self-sufficiency in case of many real-life applications, which restrict the applications of traditional methods of MCDM [24, 25].

Experts have suggested alternative strategies for handling situations where people reject their choice due to problems during the decision-making process. Factors linked to such ambiguities are handled by introducing the hypotheses of fuzzy set (FS), interval-valued fuzzy sets, intuitionistic fuzzy sets (IFSs), and hesitant fuzzy soft sets in MCDA. FSs and ordered weighted averaging were used to generate a framework for supporting decision-making for wind power in Turkey [26]. GIS systems were integrated with the methodology of fuzzy multi-criteria analysis, such as fuzzy AHP and F-TOPSIS, to identify and evaluate the available sites for the installation of onshore wind farms [27]. A methodology for determining the appropriate locations for wind power generation in Kozani, Greece was devised by Latinopoulos and Kechagia [28], who collected FSs using GIS systems.

Although all the above hypotheses have been put forward and presented, they are not able to address the concerns regarding some issues, such as ambiguous facts and knowledge. For example, when we ask an expert about his opinion on a particular statement, if he/she says that the possibility of the statement to be correct is 0.5 and incorrect is 0.6 , and the degree to which he/she is assured is not 0.2 , then such issue goes beyond the scope of FSs and IFSs.

Therefore, new theories are required to be developed. Smarandache [29] developed the concept of neutrosophic logic and neutrosophic sets (NSs), which is a general platform that ex- tends the concepts of classic and FSs, IFSs, and interval-valued IFSs [30, 31]. In contrast to IFSs and interval-valued IFSs, the indeterminacy is characterized explicitly in an NS. However, the realistic application of NSs in scientific and engineering fields might be difficult. Therefore, Wang et al. [32, 33] proposed the concepts of the single-valued neutrosophic set (SVNS) and interval neutrosophic set (INS), which are representatives of NS, and provided theoretical operators and several properties of SVNSs and INSs. SVNS represents uncertain, inaccurate, inconsistent, and incomplete information in the real world, and it is noted that the handling of indeterminate and inconsistent information is more convenient.

\section{Proposed GIS-based Framework and Methodology}

The proposed framework in this study for the identification of the best sites in a geographical region for the installation of wind farms includes various stages, which are divided as follows.

\subsection{Preliminary Study, Data Acquisition, and Formation of the Constraint Map}

The first step regarding the location of any wind-farm based project is to examine the characteristics of the study area. This includes analyzing the profile of the region, such as its natural and economic environment, demographic data, land uses, geomorphological details, and the region's wind energy potential.

\subsection{Commensuration (Standardization) of Criteria and Exclusion Areas}

Each criterion in the model uses a different quantitative and qualitative scale of measurement. This means that the criterion score value cannot be easily aggregated into one value. The critical issue is the transformation of all measurement criteria into a common scale. The process of making the raw criterion score units comparable to each other is referred to as commensuration (standardization). More detailed descriptions of the standardization approaches can be found in the published literature [11]. There are many approaches for the commensuration of raw criteria; the most commonly used approach in GIS for scaling values is the score range procedure. For the criterion that should be maximized or minimized, the above-mentioned 
approach commensurates the raw input scores as follows:

$$
\begin{aligned}
& v\left(a_{i k}\right)=\left(\max _{i}\left\{a_{i k}\right\}-a_{i k}\right) / r_{k}, \\
& v\left(a_{i k}\right)=\left(a_{i k}-\min _{i}\left\{a_{i k}\right\}\right) / r_{k},
\end{aligned}
$$

where $v\left(a_{i k}\right)$ represents the commensurate score of the $i^{\text {th }}$ cell with respect to the $k^{t h}$ criterion $(i=1,2, \ldots, m ; k=1,2, \ldots$, $n), a_{i k}$ is the score of the cell, and $\max _{i}\left\{a_{i k}\right\}$ and $\min _{i}\left\{a_{i k}\right\}$ are the maximum and minimum cell score values for the $k^{\text {th }}$ criterion, respectively; and $r_{k}$ is the range of the $k^{\text {th }}$ criterion.

$$
r_{k}=\max _{i}\left\{a_{i k}\right\}-\min _{i}\left\{a_{i k}\right\} .
$$

We use $d$ constraint criteria to eliminate areas that were unsuitable for wind farm construction. To define such areas, buffer zones were created at a particular distance from each criterion. A Boolean scale (0/1) was used to convert each cell in the input raster map to binary format 0 and 1 , where the unsuitable and suitable areas were assigned a value of 0 and 1 , respectively [28, 29, 34]. To produce a final map to be used for decision-making, the Boolean constraint map was summed up by the logical AND or OR operators [35].

\subsection{Analysis and Assessment}

After the exclusionary areas were identified and excluded, the remaining area were considered the most potential area for wind farm construction. This potentially suitable area must be evaluated to select the preferred sites. In this study, we used ArcGIS spatial analyst extension, which provides an affluent set of spatial analysis and modeling tools, and functions for both raster and vector data. The analytical capabilities of a spatial analyst facilitate spatial manipulation, generation of data based on spatial analysis, and visualization of the results of spatial analysis.

\subsection{Determination of the Subjective Weight with Single Value Neutrosophic Number-Analytic Network Pro- cess Method}

In this section, we briefly introduce some basic concepts of the analytic network process based on single-value neutrosophic numbers (SVNNs). In NSs, the variable $\mathrm{x}$ is described by three values, i.e., $x=(T, I, F)$, where " $T$ " it is the degree of truthfulness, "F" is the degree of falsehood, and "I" is the level of indeterminacy. Neutrosophic logic is able to deal with contradictions that are true and false at the same time, as long as the sum of the components is any number between -0 and $3+$ [29]. This section briefly summarizes some general concepts of SVNNs that involve operational laws and score functions [36].

Assume that $\mathrm{X}$ is a space of objects, and $\mathrm{x} \in \mathrm{X}$. A neutrosophic set A in X is defined by three functions: a truthfulnessmembership function $\mathrm{TA}(\mathrm{x})$, an indeterminacy-membership function IA(x), and a falsehood-membership function FA(x).

Definition 1. If we assume that $N_{1}=\left(T_{1}, I_{1} F_{1}\right)$, and $N_{2}=\left(T_{2}, I_{2}, F_{2}\right)$ are two SVNNs, then their operations are defined as follows:

$$
\begin{aligned}
& N_{1}+N_{2}=\left(T_{1}+T_{2}-T_{1} T_{2}, I_{1} I_{2}, F_{1} F_{2}\right), \\
& N_{1} \times N_{2}=\left(T_{1} T_{2}, I_{1}+I_{2}-I_{1} I_{2}, F_{1}+F_{2}-F_{1} F_{2}\right), \\
& N_{2} / N_{1}=\left(T_{2} / T_{1}, I_{2}-I_{1} / 1-I_{1}, F_{2}-F_{1} / 1-F_{1}\right) .
\end{aligned}
$$

Definition 2. Assuming that $N_{1}=\left(T_{1}, I_{1}, F_{1}\right)$ is an SVNN and $\mathrm{A}$ is an arbitrary positive real number, their operations are defined as follows:

$$
\begin{aligned}
& A \times N_{1}=\left(1-\left(1-T_{1}\right)^{A}, I_{1}{ }^{A}, F_{1}{ }^{A}\right), A>0, \\
& N_{1} / A=\left(1-\left(1-T_{1}\right)^{\frac{1}{A}}, I_{1}{ }^{\frac{1}{A}}, F_{1}{ }^{\frac{1}{A}}\right), A>0 .
\end{aligned}
$$

Definition 3. Assuming that $N_{1}=\left(T_{1}, I_{1}, F_{1}\right)$ is an SVNN, its score function $S\left(N_{1}\right)$ is defined as follows.

$$
S\left(N_{1}\right)=\left(3+T_{1}-2 I_{1}-F_{1}\right) / 4 .
$$

The AHP and its generalization, the ANP, are used for decisionmaking. The decision-making problems in ANP are structured as a network that provides feedback between different clusters of elements. The problems cannot be hierarchically structured as in AHP, as they involve dependency, interaction, and feedback between higher-and lower-level clusters, and within clusters at the same level [37]. A network is used to transfer the effect from one cluster to a different cluster (outer dependency). Elements within a cluster also rely on each other, which leads to dependencies within iterations of a loop, referred to as an inner dependent loop [37, 38]. Under such conditions, the SVNNs are combined with the ANP method. Based on the SVNN-ANP method, the steps for obtaining the subjective weights are as follows:

Step 1: Describe and decompose the decision problem in a network model. To demonstrate the spatial ANP method, a standard ANP network with a single control criterion (goal), clusters (objectives or criteria), nodes (attributes or sub-criteria), and alternatives were considered, as shown in Figure 1. Here, the 


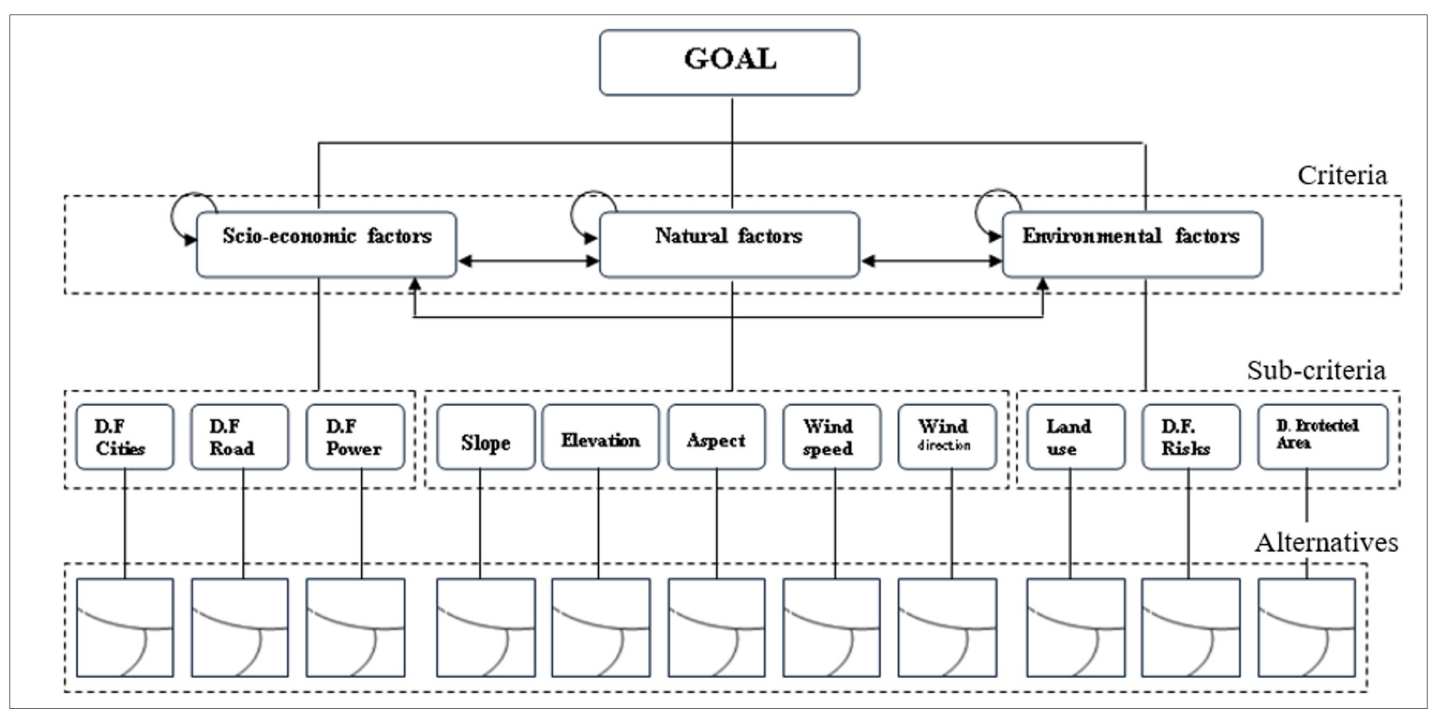

Figure 1. A GIS-based neutrosophic ANP method.

Table 1. The single value neutrosophic scale for the comparison matrix [36]

\begin{tabular}{llll}
\hline \multicolumn{1}{c}{ Linguistic term } & Neutrosophic set & \multicolumn{1}{c}{ Linguistic term } & $\begin{array}{c}\text { Reciprocal } \\
\text { neutrosophic set }\end{array}$ \\
\hline Extremely highly preferred & $(0.90,0.10,0.10)$ & Mildly lowly preferred & $(0.10,0.90,0.90)$ \\
Extremely preferred & $(0.85,0.20,0.15)$ & Mildly preferred & $(0.15,0.80,0.85)$ \\
Very strongly to extremely preferred & $(0.80,0.25,0.20)$ & Mildly preferred to very lowly preferred & $(0.20,0.75,0.80)$ \\
Very strongly preferred & $(0.75,0.25,0.25)$ & Very lowly preferred & $(0.25,0.75,0.75)$ \\
Strongly preferred & $(0.70,0.30,0.30)$ & Lowly preferred & $(0.30,0.70,0.70)$ \\
Moderately highly to strongly preferred & $(0.65,0.30,0.35)$ & Moderately lowly preferred to lowly preferred & $(0.35,0.70,0.65)$ \\
Moderately highly preferred & $(0.60,0.35,0.40)$ & Moderately lowly preferred & $(0.40,0.65,0.60)$ \\
Equally to moderately preferred & $(0.55,0.40,0.45)$ & Moderately to equally preferred & $(0.45,0.60,0.55)$ \\
Equally preferred & $(0.50,0.50,0.50)$ & Equally preferred & $(0.50,0.50,0.50)$ \\
\hline
\end{tabular}

alternatives are depicted as a cell (raster) or polygon (vector).

Step 2: Identify inner-outer dependencies. This step requires defining all relationships that might exist in the clusters of decision dilemma and the feedback system. The network structure problem was designed based on the inner-outer dependencies.

Step 3: Determine the single-value neutrosophic scales corresponding to the linguistic term for evaluation. The interrelationship between factors was determined by neutrosophic pairwise comparisons of one factor to another. To estimate this relationship, the linguistic scale with the corresponding SVNN was determined as shown in Table 1.

Step 4: Establish pairwise comparisons among the factors. The relative strength of each pair of factors forms a comparison matrix, and the preference of the experts' threshold in the comparison matrix was represented using SVNN. The pairwise comparison matrix $\mathrm{P}$ was described to express the preferences of the DM.

Step 5: Normalize matrices and estimate the relative priorities. The following four steps were used to normalize the matrices and estimate the neutrosophic priorities [39].

1. Add the values in each column of Table 1 using Eq. (4).

2. Divide each value in a column by the sum of the values in the entire column using Eq. (6).

3. Calculate the criteria weight (eigenvector) using Eq. (4) to add the elements in each row and divide the sum by the number of elements in the row using Eq. 8).

4. Check the consistency by converting the single-value neutrosophic preference into their crisp preference, and then using the Saaty check consistency method to verify the consistency ratio (CR) [40]. Generally, a CR is considered acceptable if its 
value is 0.10 or less.

Step 6: Formulate the initial and weighted neutrosophic super-matrix. Once several paired neutrosophic comparisons were completed for every interdependent connection, the initial neutrosophic super-matrix was designed. The initial neutrosophic super-matrix was constructed from the neutrosophic weight priorities obtained from the neutrosophic pairwise comparison procedure between clusters and nodes. The neutrosophic priority weight must be replaced with the appropriate columns of the initial neutrosophic super-matrix, with respect to which the pairwise comparisons are performed.

Step 7: Limitation of neutrosophic super-matrix and final priorities. The neutrosophic weighted super-matrix was transformed into a column stochastic limit super-matrix. This was done in three phases. The first consisted of de-neutrosphication of values in the weighted super-matrix using Eq. (9) to obtain the de-neutrosophicated weighted super-matrix (crisp weights) [36]. The second phase consisted of normalizing the matrix by summing the values of the individual columns to one. The last phase consisted of repeatedly raising the normalized supermatrix to different powers until all the columns in the supermatrix had the same values. The subjective weights of the factors, obtained from the results, were used in the ArcGIS to determine alternative matrices.

\subsection{Suitability Map Creation}

A percentage of influence was assigned to each data layer according to its relative importance. Weight is reported in relative percentage, and the sum of the \% influence weights must add up to 100 . A weighted overlay was used to combine the criteria maps and produce the final suitability index for suitable areas by multiplying each classified data layer by their weight factor.

$$
S=\sum\left(X_{i j} \cdot W_{j}\right)
$$

where $S$ is composite suitability score, $X_{i j}$ is attribute score $i$ for factor $j$, and $W_{j}$ is the weight assigned to each factor $j$. The ArcGIS spatial analyst "times" tool that multiplies the values of two rasters on a cell-by-cell basis was used to avoid restricted areas in our study area, and subsequently the final suitability map was generated.

$$
S=\sum\left(X_{i j} \cdot W_{j}\right) * \prod C_{l}
$$

where $S$ is composite suitability score, $X_{i j}$ is attribute score $i$ for factor $j, W_{j}$ is weights assigned to each factor $j$, and $\prod C_{l}$ is the constraint binary map description of symbols.

\subsection{Determination of the Objective Weight using Shannon's Entropy Method}

The Shannon entropy method was proposed in 1948 when Claude Shannon introduced the entropy application in communication theory [41]. In Shannon's entropy method, the probability distribution of a given state or event are calculated. In other words, the entropy evaluates the expected information content of an event, in such a way that high entropy indicates that the probability of the event is high and low entropy indicates a low probability of the event. In MCDM, events are criteria, and the probability of occurrence of an event is given by the weight of each criterion. The Shannon entropy method consists of the following three procedures:

We assume that $X_{i j}$ is a density matrix of the site selection problem.

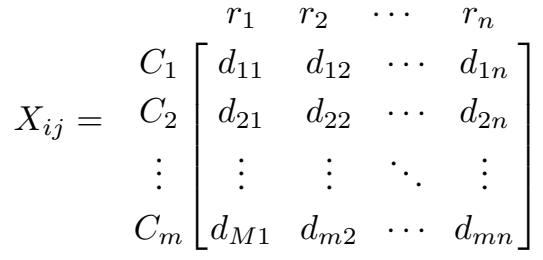

where $C_{i}(i=1,2, \ldots, m)$ represents the $i^{\text {th }}$ criteria, $r_{j}$ $(j=1,2, \ldots, n)$ represents the $j^{\text {th }}$ reclassified classes related to the $i^{\text {th }}$ criteria, and $d_{i j}$ is a crisp value indicating the pixel density of each class $r_{j}$ with respect to each criterion $C_{i}$.

Procedure 1. Calculate the information of $X_{i j}$ as $P_{i j}$ :

$$
P_{i j}=\frac{d_{i j}}{\sum_{i=1}^{m} d_{i j}}, \forall i, j
$$

Procedure 2. Calculate the entropy values $E_{j}$ as:

$$
E_{j}=-K \sum_{i=1}^{n}\left(P_{i j} \ln P_{i j}\right)
$$

where the constant $K$ is defined as:

$$
K=\frac{1}{\ln n},
$$

where $n$ represents the number of re-classified classes for each criterion.

Procedure 3. The objective weights based on the Shannon entropy criterion for each alternative can be calculated as follows: 


$$
\begin{gathered}
w_{j}=\frac{1-E_{j}}{\sum_{i=1}^{n}\left(1-E_{j}\right)}, \\
W_{i j}= \\
A_{1}\left[\begin{array}{cccc}
C_{1} & C_{2} & \cdots & C_{n} \\
w_{11} & w_{12} & \cdots & w_{1 n} \\
w_{21} & w_{22} & \cdots & w_{2 n} \\
\vdots & \vdots & \ddots & \vdots \\
A_{m}\left[\begin{array}{cccc}
w_{M 1} & w_{m 2} & \cdots & w_{m n}
\end{array}\right]
\end{array}\right.
\end{gathered}
$$

where $A_{i}(i=1,2, \ldots, m)$ denotes the $i^{\text {th }}$ alternative, $C_{j}$ $(j=1,2, \ldots, n)$ denotes the $j^{\text {th }}$ criterion related to the $i^{\text {th }}$ alternative, and $w_{i j}$ is a crisp value indicating the performance rating of each alternative $A_{i}$ with respect to the individual criterion $\left(C_{j}\right)$.

\subsection{Ranking Alternatives with the Hybrid PROMETHEE- TOPSIS Method}

\subsubsection{The PROMETHEE II method}

The preference ranking organization method for enrichment evaluation (PROMETHEE) is an MCDM outranking method proposed by Brans (1982), and expanded by Brans and Vincke [42]. The PROMETHEE is fully adapted to problems where a finite number of alternatives must be arranged according to a number of otherwise conflicting criteria [43]. More information and details about the PROMETHEE method can be found in the literature [44]. In this study, the PROMETHEE II method was used to rank the alternatives with respect to the different criteria. The implementation steps of PROMETHEE II are as follows:

Let us assume that $C=\{1,2, \ldots, n\}$ is a set of $n^{\text {th }}$ criteria, and $A=\{a, b, \ldots, m\}(m \geq 2)$ is a set of possible $m^{\text {th }}$ alternatives. each criterion $C_{n}$ has its weight $w_{c}$, which represents its relative importance and its summation is given as Eq. (18).

$$
\sum_{c=1}^{n} W_{c}=1
$$

Step 1: Evaluate each alternative $A_{m}$ with respect to the $n^{\text {th }}$ evaluation criteria, and generate the total alternate evaluation matrix $E_{A C}$ according to Eq. (19).

$$
\left.E_{m n}=\begin{array}{cccc}
C_{1} & C_{2} & \cdots & C_{n} \\
A_{1} & A_{2} \\
\vdots & A_{m} \\
e_{11} & e_{12} & \cdots & e_{1 n} \\
e_{21} & e_{22} & \cdots & e_{2 n} \\
\vdots & \vdots & \ddots & \vdots \\
e_{M 1} & e_{m 2} & \cdots & d e_{m n}
\end{array}\right]
$$

where $e_{m n}$ is the evaluation score value of the alternative $A_{m}$ with respect to criteria $C_{n}$, which is provided by the DMs.

Step 2: Normalize the decision matrix to range 0-1 using $R_{m n}$ values for each column according to Eq. (20).

$$
R_{m n}=\frac{\left[e_{m n}-\min \left(e_{m n}\right)\right]}{\left[\max \left(e_{m n}\right)-\min \left(e_{m n}\right)\right]} .
$$

Step 3: Determine the deviations in evaluation by pairwise comparisons according to Eq 21]

$$
d_{c}(a, b)=g_{c}(a)-g_{c}(b)
$$

where $a$ and $b$ are two alternatives, and $d_{c}(a, b)$ represents the difference between the evaluations of $a$ and $b$ for each criterion

Step 4: Calculate the preference function according to Eq. (22).

$$
P_{c}(a, b)= \begin{cases}f\left[d_{c}(a, b)\right], & \left(g_{c}(a)>g_{c}(b)\right), \\ 0, & \left(g_{c}(a) \leq g_{c}(b)\right)\end{cases}
$$

where $P_{c}(a, b)$ is the preference function that translates the difference between the evaluations of alternative $a$ in regards to alternative $b$ for each criterion into a degree ranging $0-1$.

Step 5: Calculate the aggregated preference index according to Eq. 23

$$
\pi(a, b)=\int_{c=1}^{n} P(a, b) w_{C},
$$

where $w_{C}$ is the weight associated with each criterion. In addition, $\pi(a, b)$ is the summation weight $P(a, b)$ for each criterion.

Step 6: Determine the positive outranking flow (leaving flow) and the negative outranking flow (entering flow) according to Eqs. (24) and 25.

$$
\begin{aligned}
\phi^{+}(a) & =\frac{1}{m-1} \sum_{x \in A} \pi(a, x), \\
\phi^{-}(a) & =\frac{1}{m-1} \sum_{x \in A} \pi(x, a) .
\end{aligned}
$$

Step 7: Calculate the net outranking flow for each alternative

$$
\phi(a)=\phi^{+}(a)-\phi^{-}(a) .
$$

Step 8: Determine the ranking of all possible alternatives according to the values of $\phi(a)$. The best alternative is the one with a higher value of $\phi(a)$. 


\subsubsection{The TOPSIS method}

The technique for TOPSIS, which was first introduced in 1981 by Hwang and Yoon [45], is a classical MCDM method. In the TOPSIS method, every problem is considered as a geometric system consisting of $M$ points in an $\mathrm{N}$-dimensional space, and the preferred alternative is the one with the minimum Euclidean distance from the positive-ideal solution and the maximum Euclidean distance from the negative-ideal solution. The TOPSIS method is consisted of the following six steps:

Step 1: Normalize the decision matrix using the relation as follows:

$$
\bar{X}_{i j}=\frac{X_{i j}}{\sqrt{\sum_{j=1}^{n} X_{i j}^{2}}} .
$$

Step 2: Multiply each column in the normalized matrix by its associated weight to obtain the weighted matrix

$$
V_{i j}=W_{i j} \times \bar{X}_{i j}
$$

Step 3: Determine the positive and the negative ideal solution, where

$$
\begin{aligned}
& V_{j}^{+}=\text {indicates the ideal (best) value, } \\
& V_{j}^{-}=\text {indicates the ideal (worst) value. }
\end{aligned}
$$

Step 4: Calculate the Euclidian distance from the ideal best and the ideal worst solution as follows:

$$
\begin{aligned}
& S_{i}^{+}=\left[\int_{j=1}^{m}\left(V_{i j}-V_{j}^{+}\right)^{2}\right]^{0.5}, \\
& S_{i}^{-}=\left[\int_{j=1}^{m}\left(V_{i j}-V_{j}^{-}\right)^{2}\right]^{0.5} .
\end{aligned}
$$

Step 5: Calculate the relative closeness of the ideal solution using Eq. 33.

$$
P_{i}=\frac{S_{i}^{-}}{S_{i}^{+}+S_{i}^{-}}
$$

Step 6: Select the alternative with $P_{i}$ closest to 1 .

\section{Case Study}

An extended case study is provided in this section to demonstrate the effectiveness of the proposed MCDM method. The case study area was the Sinai Peninsula in the northeastern corner of the Arab Republic of Egypt. Sinai is a triangular peninsula with an area of more than $16,000 \mathrm{~km}^{2}$, equivalent to $6 \%$ of total the area of Egypt. It lies between $27^{\circ} 43^{\prime}-31^{\circ} 19^{\prime}$ $\mathrm{N}$ and $32^{\circ} 19^{\prime}-34^{\circ} 54^{\prime} \mathrm{E}$. The Peninsula is situated between the Gulf of Aqaba and the Gulf of Suez, and is bounded from the north by the Mediterranean Sea [46, 47]. The southern region of the peninsula has complex high mountains like Mount Catherine, standing at a height of 2,638 $\mathrm{m}$ above the mean sea level. Several mountain peaks in the neighboring region exceed the height of 2,000 $\mathrm{m}$. The northern plains extending from the Level 0 of the Sinai region gently cascade towards its inner region, and are almost devoid of levels with heights exceeding $500 \mathrm{~m}$ only in some mountains. The Sinai Peninsula has a population of approximately 600,000 people. The requisite data were collected from numerous resources, including governmental agencies, open sources, and relevant literature such as the National Authority for Remote Sensing \& Space Sciences (NARS), Egyptian Meteorological Authority (EMA), New and Renewable Energy Authority (NREA), Egyptian General Survey Authority (ESA), NASA Power Prediction of Worldwide Energy Resources, United States Geological Survey (USGS), and the Egyptian Environmental Affairs Agency (EEAA).

The combination of GIS and remote sensing technology have been used to process, integrate, and analyze spatial data. The software used for this study was ArcGIS10.3 and Global Mapper v17.1, due to their efficiency in generating the wind farm site selection model. A pairwise comparison of linguistic judgments obtained from experts in Egypt are shown in the next section. The weights of the criteria were generated using SVNN and ANP, which are mathematical models implemented in Microsoft Excel. The procedures for the application case are described below.

\subsection{Preliminary Study, Data Acquisition and Formation of the Constraint Map}

For our research, we used a dataset that was comprised of topographic, hydrologic, geological, and climatic factors. Based on several published literatures and case studies concerning wind farm site selection and local conditions, different criteria were reviewed. For this study, we selected 11 criteria to evaluate the suitable sites for wind farms. These criteria were classified into three main groups that play an important role in the ANP method, i.e., natural, environmental, and socioeconomic factors (detailed in Section 4.2). Table 2 shows the three criteria and eleven factors that have a significant influence on the selection of suitable sites for wind farm construction. 
Table 2. Determination and explanation of the main criteria and factors

\begin{tabular}{|c|c|c|}
\hline Cluster Name & Sub-criteria name & References \\
\hline Natural Factors (C1) & $\begin{array}{l}\text { C11 - Wind direction } \\
\text { C12 - Aspect } \\
\text { C13 - Elevation } \\
\text { C14 - Slope } \\
\text { C15 - Wind speed }\end{array}$ & $\begin{array}{l}\text { The location of wind turbines is determined by the prevailing } \\
\text { wind direction in order to be effective. } \\
{[48]} \\
{[21],[49],[50]} \\
{[51],[52]}\end{array}$ \\
\hline Socio-Economic Factors (C2) & $\begin{array}{l}\text { C21 - Dist. from power lines } \\
\text { C22 - Dist. from cities/villages } \\
\text { C23 - Dist. from main roads }\end{array}$ & $\begin{array}{l}{[48]} \\
{[48]} \\
{[48]}\end{array}$ \\
\hline Environmental Factors (C3) & $\begin{array}{l}\text { C31 - Land Cover/Land Use } \\
\text { C32 - Dist. from protected areas } \\
\text { C33 - Dist. from risks areas }\end{array}$ & $\begin{array}{l}\text { [58], [54] } \\
\text { All the mechanical parts of wind power turbines should be } \\
\text { kept away from the water To prevent damage to the turbine } \\
\text { components, wind turbine fans are lowered and disconnected. }\end{array}$ \\
\hline
\end{tabular}

This study depends on numerous types of data that cover natural, environmental, and socioeconomic factors for accessing the suitability of a wind farm site. The advanced spaceborne thermal emission and reflection radiometer (ASTER) and the global digital elevation model (GDEM) v2 worldwide elevation data (1 arc-second resolution) used in this study to prepare slope, elevation, and aspect maps for the Sinai Peninsula study area using the ArcGIS Spatial Analyst tool. The topographic map scale 1:100,000 published by the Egyptian General Survey Authority is mainly used to produce different data layers for airports, urban areas, cities, power transmission lines, rivers, lakes, protected areas, and geographical names. The Egyptian road map with scale of 1:400,000, issued by the General Authority for roads and bridges, 1988 was used to produce data layers for roads. The maps were considered as GIS layers for the entire area of the Sinai Peninsula, and projected into the coordinates WGS_1984_UTM_Zone_36N of the Universal Transverse Mercator System (UTM).

Wind data were acquired from the Egyptian Wind Atlas, developed in collaboration with the Danish RISO and the EMA. Since the data were not freely available online, we purchased it from the NREA. The model was prepared using meteorological data from the nearest twelve climate stations. In addition, we paired our data with historical wind data using the NASA power data access viewer, and extrapolated them with monthly averages in the period between 1981 and 2018, at a height of $10 \mathrm{~m}$ and $50 \mathrm{~m}$, respectively, due to the inadequate wind information. Subsequently, all vector datasets were converted to a raster data set. The dataset within the boundary of the study area was clipped or masked, and it was ensured that all cell sizes equaled $30 \times 30$.

\subsection{Commensuration (Standardization) of Criteria and Def- inition of Exclusion Areas}

In this step, the evaluation layers were scaled from (0) to (10). This was done by dividing the maximum grading value to be given, in this case one (1), by the class number, starting with the class that considers the highest grading value to the class that considers the lowest. The obtained grading values were then multiplied by 10 to obtain the score. Subsequently, every constraint criterion was presented to the GIS by a unique layer that is called a constraint layer. The constraint layers possess a value of zero (0) when deemed unsuitable for wind power generation, and a value of one (1) when suitable. The defined restriction criteria, the list of exclusion criteria, and the corresponding buffer distance were determined according to the literature reviews and expert's opinions. The final restriction area map was generated by multiplying different constraint layers using the spatial analyst toolbox.

\subsection{Analysis and Assessment}

In this stage, the Euclidean distance and the reclassification tools were used in the ArcMap environment to analyze the adequate location of the wind farms. The Euclidean distance method measures the Euclidean distance to the nearest source 
Table 3. Pairwise comparison matrix for natural criteria for land-use and priority vector $(\mathrm{CR}=0.009)$

\begin{tabular}{|c|c|c|c|c|}
\hline C31 & C15 & C14 & C13 & Weights \\
\hline $\mathrm{C} 15$ & $(0.50,0.50,0.50)$ & $(0.55,0.40,0.45)$ & $(0.60,0.35,0.40)$ & $(0.629,0.331,0.371)$ \\
\hline C14 & $(0.45,0.60,0.55)$ & $(0.50,0.50,0.50)$ & $(0.55,0.40,0.45)$ & $(0.572,0.4256,0.428)$ \\
\hline $\mathrm{C} 13$ & $(0.40,0.65,0.60)$ & $(0.45,0.60,0.55)$ & $(0.50,0.50,0.50)$ & $(0.515,0.522,0.485)$ \\
\hline
\end{tabular}

Table 4. The limitation super-matrix

\begin{tabular}{lccccccccccc}
\hline & C11 & C12 & C13 & C14 & C15 & C21 & C22 & C23 & C31 & C32 & C33 \\
\hline C11 & 0.0831 & 0.0831 & 0.0831 & 0.0831 & 0.0831 & 0.0831 & 0.0831 & 0.0831 & 0.0831 & 0.0831 & 0.0831 \\
C12 & 0.0866 & 0.0866 & 0.0866 & 0.0866 & 0.0866 & 0.0866 & 0.0866 & 0.0866 & 0.0866 & 0.0866 & 0.0866 \\
C13 & 0.0970 & 0.0970 & 0.0970 & 0.0970 & 0.0970 & 0.0970 & 0.0970 & 0.0970 & 0.0970 & 0.0970 & 0.0970 \\
C14 & 0.0969 & 0.0969 & 0.0969 & 0.0969 & 0.0969 & 0.0969 & 0.0969 & 0.0969 & 0.0969 & 0.0969 & 0.0969 \\
C15 & 0.0930 & 0.0930 & 0.0930 & 0.0930 & 0.0930 & 0.0930 & 0.0930 & 0.0930 & 0.0930 & 0.0930 & 0.0930 \\
C21 & 0.0921 & 0.0921 & 0.0921 & 0.0921 & 0.0921 & 0.0921 & 0.0921 & 0.0921 & 0.0921 & 0.0921 & 0.0921 \\
C22 & 0.0968 & 0.0968 & 0.0968 & 0.0968 & 0.0968 & 0.0968 & 0.0968 & 0.0968 & 0.0968 & 0.0968 & 0.0968 \\
C23 & 0.0963 & 0.0963 & 0.0963 & 0.0963 & 0.0963 & 0.0963 & 0.0963 & 0.0963 & 0.0963 & 0.0963 & 0.0963 \\
C31 & 0.0884 & 0.0884 & 0.0884 & 0.0884 & 0.0884 & 0.0884 & 0.0884 & 0.0884 & 0.0884 & 0.0884 & 0.0884 \\
C32 & 0.0850 & 0.0850 & 0.0850 & 0.0850 & 0.0850 & 0.0850 & 0.0850 & 0.0850 & 0.0850 & 0.0850 & 0.0850 \\
C33 & 0.0850 & 0.0850 & 0.0850 & 0.0850 & 0.0850 & 0.0850 & 0.0850 & 0.0850 & 0.0850 & 0.0850 & 0.0850 \\
\hline
\end{tabular}

for each cell, and in this case, it was used to define the proximity of the already available infrastructures. The reclassify tool reclassifies the raster using relevant statistics, and classifies them within given intervals. In our study, the reclassify tool was used to evaluate the suitability of the sites for all input raster layers.

\subsection{Determination of the Subjective Weight with Single Value Neutrosophic Number-Analytic Network Pro- cess Method}

The relationship between the factors of different criteria was analyzed using an SVNN in a network structure, as shown in Figure 1. Pairwise comparisons were conducted on the example to demonstrate the inter-dependencies using SVNNs with the scale provided in Table 1. Table 3 shows an example of the natural criteria concerning land use factors. The remaining evaluations were performed in the same manner. The relative importance weights were obtained according to Eqs. (4), (6), and (8). After checking the CR (less than 0.10), we accepted the comparison results. These priorities, obtained using SVNNs, formed the submatrices of the super-matrix. Subsequently, the initial neutrosophic super-matrix was converted to a weighted neutrosophic super-matrix by multiplying each node in a cluster of the initial neutrosophere by the neutrosophic weight of the cluster $\left(w_{\text {Factors }}\right)$, which was determined by comparing various clusters. Subsequently, it was converted to a de-neutrosophicated-weighted super-matrix (crisp weights) using Eq. (9). After that, each column was normalized, and raised to a power of 20 to obtain the subjective weight of each factor, as shown in Table 4.

\subsection{Suitability Map Creation}

All layers were merged to calculate the final appropriate score of the study area using the "Weighted Overlay" tool. The suitability score is classified into four classes: highly suitable, moderately suitable, least suitable, and not suitable. Highly suitable areas with a raster value of " 4 " were extracted using the "Extract By Attribute" tool. Figure 2(a) displays the extracted extremely suitable areas with a surface area of 2,874 $\mathrm{km}^{2}$. Subsequently, we used the "Majority Filter" tool of the Generalization toolset with eight neighbors and the "Majority Replacement" to replace the suitable area cells in the extracted raster based on the majority of their contiguous neighboring cells. The filtering process further reduced the highly suitable area to $2,571 \mathrm{~km}^{2}$, as shown in Figure 2(b). 


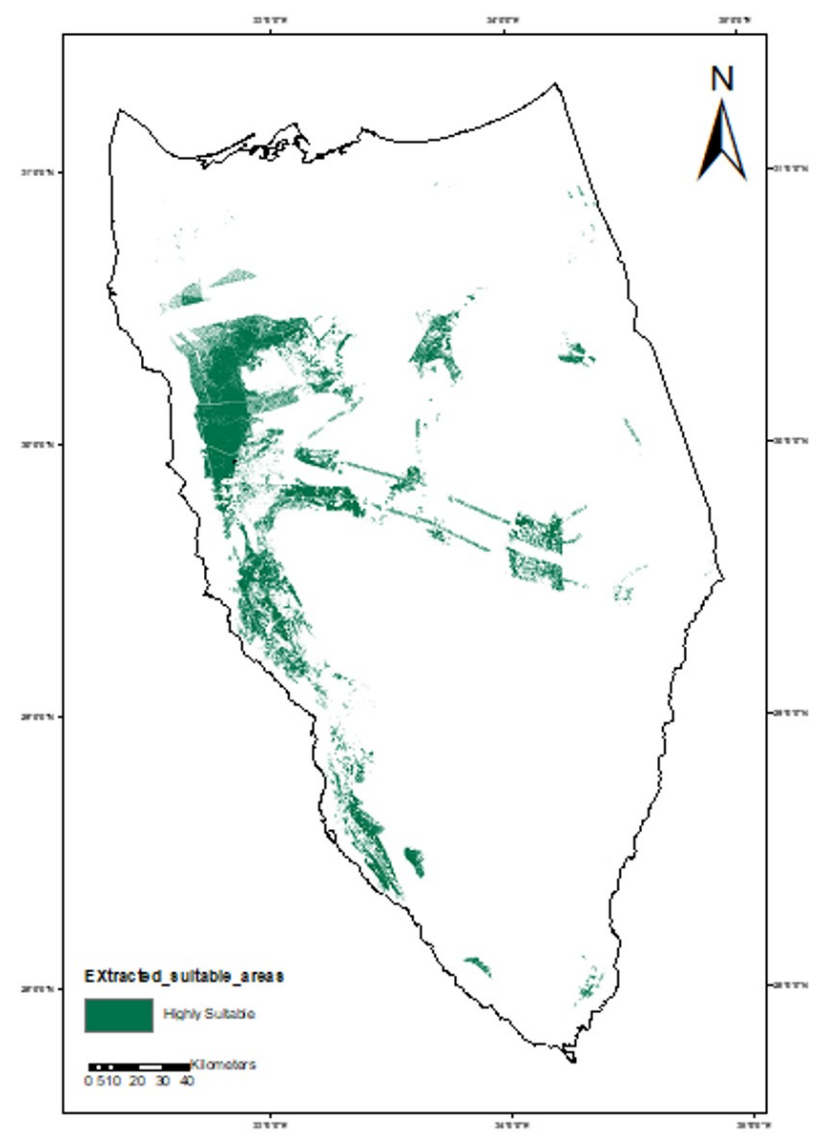

(a)

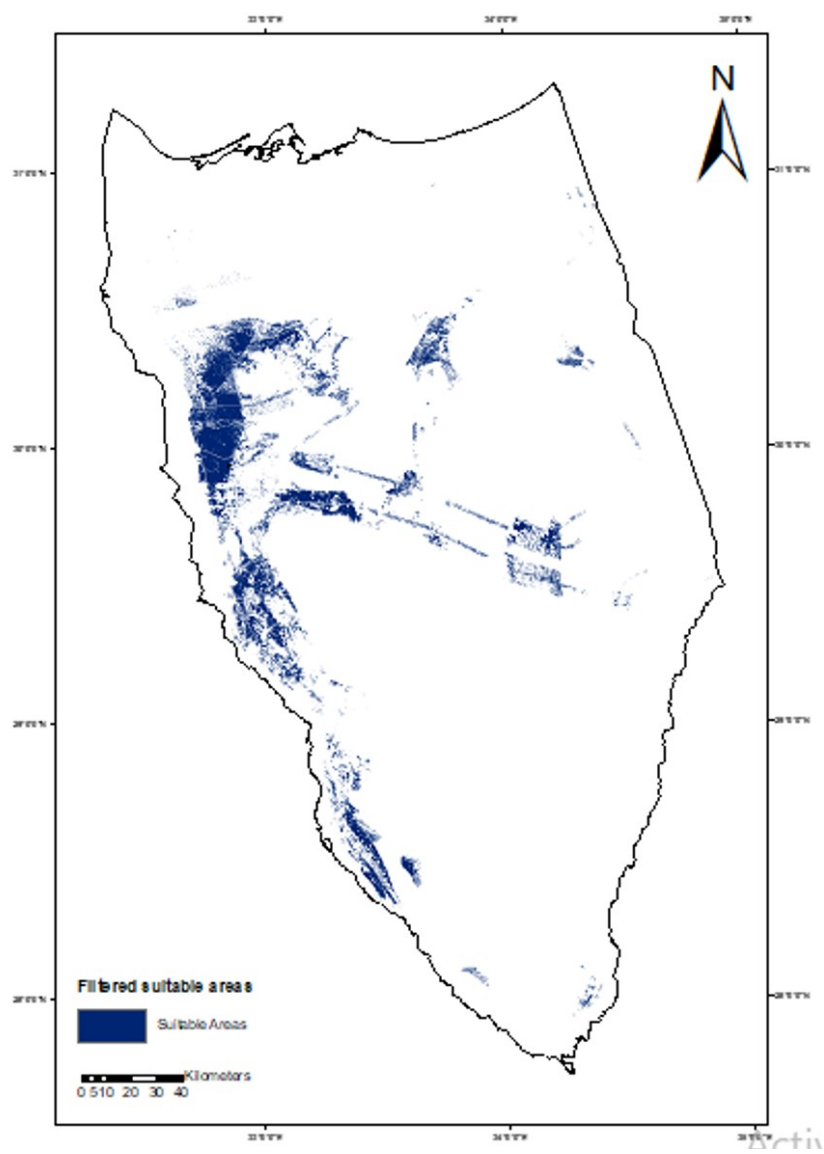

(b)

Figure 2. Highly suitable sites for wind farm construction: (a) extracted suitable sites and (b) filtered suitable sites.

\subsection{Determination of the Objective Weight using Shan- non's Entropy Method}

Step 1: Use Eq. (12) to determine all possible alternative zones and construct the density matrix for each alternative. The alternatives were evaluated separately with respect to all decision criteria, and the $P_{i j}, E_{j}, w_{j}$ values were calculated using Eqs. (13) and 116 for each alternative.

Step 2: Generate the performance rating matrix $W_{i j}$ for all possible zones with respect to all criteria. Eq. (34) presents the performance rating matrix for all alternative zones (A, B, $\mathrm{C}$, and D) for the construction of a new wind farm in the Sinai Peninsula with respect to 13 criteria.

$$
W_{i j}=\left[\begin{array}{ccccccc}
1.1 & 0.2 & 1.2 & 1 & 1.9 & 0.2 & 0.2 \\
2 & 1 & 1.2 & 0.7 & 0.5 & 0.5 & 0.8 \\
2.1 & 0 & 1 & 0.2 & 0.9 & 1.4 & 0.4 \\
1.1 & 0.2 & 1.1 & 1.9 & 1 & 0.8 & 0.3
\end{array}\right.
$$

$\left.\begin{array}{cccccc}0.5 & 1.1 & 0.3 & 0.2 & 0.6 & 1.5 \\ 0.5 & 0.7 & 0.3 & 1 & 0.8 & 1 \\ 0.8 & 0.6 & 0.6 & 0.1 & 0.7 & 1 \\ 0.5 & 0.6 & 0.6 & 0.7 & 0.4 & 0.8\end{array}\right]$.

The ranking alternatives were determined using the hybrid PROMETHEE-TOPSIS Method. The steps used are as follows:

Step 3: For each column, the PROMETHEE-II normalization was used in Eq. 20, to normalize the performance entropy matrix $W_{i j}$ in a range of $0-1$ for obtaining the normalized matrix $R_{i j}$, as shown in Eq. 35.

$$
R_{i j}=\left[\begin{array}{ccccccc}
0 & 0.2 & 1 & 0.47 & 1 & 0 & 0 \\
0.9 & 1 & 1 & 0.29 & 0 & 0.25 & 1 \\
1 & 0 & 0 & 0 & 0.29 & 1 & 0.33 \\
0 & 0.2 & 0.5 & 1 & 0.36 & 0.5 & 0.17
\end{array}\right.
$$


Table 5. Deviations between any two potential alternatives with respect to criteria $\mathrm{C}_{j}$

\begin{tabular}{cccccccccccccc}
\hline & $\boldsymbol{C}_{\mathbf{1 1}}$ & $\boldsymbol{C}_{\mathbf{1 2}}$ & $\boldsymbol{C}_{\mathbf{1 3}}$ & $\boldsymbol{C}_{\mathbf{1 4}}$ & $\boldsymbol{C}_{\mathbf{1 5}}$ & $\boldsymbol{C}_{\mathbf{2 1}}$ & $\boldsymbol{C}_{\mathbf{2 2}}$ & $\boldsymbol{C}_{\mathbf{2 3}}$ & $\boldsymbol{C}_{\mathbf{3 1}}$ & $\boldsymbol{C}_{\mathbf{3 2}}$ & $\boldsymbol{C}_{\mathbf{3 3}}$ & $\boldsymbol{C}_{\mathbf{3 4}}$ & $\boldsymbol{C}_{\mathbf{3 5}}$ \\
\hline$P(A, B)$ & -0.9 & -0.8 & 0 & 0.18 & 1 & -0.25 & -1 & 0 & 0.8 & 0 & -0.89 & -0.5 & 0.71 \\
$P(A, C)$ & -1 & 0.2 & 1 & 0.47 & 0.71 & -1 & -0.33 & -1 & 1 & -1 & 0.11 & -0.25 & 0.71 \\
$P(A, D)$ & 0 & 0 & 0.5 & -0.53 & 0.64 & -0.5 & -0.17 & 0 & 1 & -1 & -0.56 & 0.5 & 1 \\
$P(B, A)$ & 0.9 & 0.8 & 0 & -0.18 & -1 & 0.25 & 1 & 0 & -0.8 & 0 & 0.89 & 0.5 & -0.71 \\
$P(B, C)$ & -0.1 & 1 & 1 & 0.29 & -0.29 & -0.75 & 0.67 & -1 & 0.2 & -1 & 1 & 0.25 & 0 \\
$P(B, D)$ & 0.9 & 0.8 & 0.5 & -0.71 & -0.36 & -0.25 & 0.83 & 0 & 0.2 & -1 & 0.33 & 1 & 0.29 \\
$P(C, A)$ & 1 & -0.2 & -1 & -0.47 & -0.71 & 1 & 0.33 & 1 & -1 & 1 & -0.11 & 0.25 & -0.71 \\
$P(C, B)$ & 0.1 & -1 & -1 & -0.29 & 0.29 & 0.75 & -0.67 & 1 & -0.2 & 1 & -1 & -0.25 & 0 \\
$P(C, D)$ & 1 & -0.2 & -0.5 & -1 & -0.07 & 0.5 & 0.17 & 1 & 0 & 0 & -0.67 & 0.75 & 0.29 \\
$P(D, A)$ & 0 & 0 & -0.5 & 0.53 & -0.64 & 0.5 & 0.17 & 0 & -1 & 1 & 0.56 & -0.5 & -1 \\
$P(D, B)$ & -0.9 & -0.8 & -0.5 & 0.71 & 0.36 & 0.25 & -0.83 & 0 & -0.2 & 1 & -0.33 & -1 & -0.29 \\
$P(D, C)$ & -1 & 0.2 & 0.5 & 1 & 0.07 & -0.5 & -0.17 & -1 & 0 & 0 & 0.67 & -0.75 & -0.29 \\
\hline
\end{tabular}

Table 6. Preference function

\begin{tabular}{llllllllllllll}
\hline & $\boldsymbol{C}_{\mathbf{1 1}}$ & $\boldsymbol{C}_{\mathbf{1 2}}$ & $\boldsymbol{C}_{\mathbf{1 3}}$ & $\boldsymbol{C}_{\mathbf{1 4}}$ & $\boldsymbol{C}_{\mathbf{1 5}}$ & $\boldsymbol{C}_{\mathbf{2 1}}$ & $\boldsymbol{C}_{\mathbf{2 2}}$ & $\boldsymbol{C}_{\mathbf{2 3}}$ & $\boldsymbol{C}_{\mathbf{3 1}}$ & $\boldsymbol{C}_{\mathbf{3 2}}$ & $\boldsymbol{C}_{\mathbf{3 3}}$ & $\boldsymbol{C}_{\mathbf{3 4}}$ & $\boldsymbol{C}_{\mathbf{3 5}}$ \\
\hline$P(A, B)$ & 0.00 & 0.00 & 0.00 & 0.18 & 1.00 & 0.00 & 0.00 & 0.00 & 0.80 & 0.00 & 0.00 & 0.00 & 0.71 \\
$P(A, C)$ & 0.00 & 0.20 & 1.00 & 0.47 & 0.71 & 0.00 & 0.00 & 0.00 & 1.00 & 0.00 & 0.11 & 0.00 & 0.71 \\
$P(A, D)$ & 0.00 & 0.00 & 0.50 & 0.00 & 0.64 & 0.00 & 0.00 & 0.00 & 1.00 & 0.00 & 0.00 & 0.50 & 1.00 \\
$P(B, A)$ & 0.90 & 0.80 & 0.00 & 0.00 & 0.00 & 0.25 & 1.00 & 0.00 & 0.00 & 0.00 & 0.89 & 0.50 & 0.00 \\
$P(B, C)$ & 0.00 & 1.00 & 1.00 & 0.29 & 0.00 & 0.00 & 0.67 & 0.00 & 0.20 & 0.00 & 1.00 & 0.25 & 0.00 \\
$P(B, D)$ & 0.90 & 0.80 & 0.50 & 0.00 & 0.00 & 0.00 & 0.83 & 0.00 & 0.20 & 0.00 & 0.33 & 1.00 & 0.29 \\
$P(C, A)$ & 1.00 & 0.00 & 0.00 & 0.00 & 0.00 & 1.00 & 0.33 & 1.00 & 0.00 & 1.00 & 0.00 & 0.25 & 0.00 \\
$P(C, B)$ & 0.10 & 0.00 & 0.00 & 0.00 & 0.29 & 0.75 & 0.00 & 1.00 & 0.00 & 1.00 & 0.00 & 0.00 & 0.00 \\
$P(C, D)$ & 1.00 & 0.00 & 0.00 & 0.00 & 0.00 & 0.50 & 0.17 & 1.00 & 0.00 & 0.00 & 0.00 & 0.75 & 0.29 \\
$P(D, A)$ & 0.00 & 0.00 & 0.00 & 0.53 & 0.00 & 0.50 & 0.17 & 0.00 & 0.00 & 1.00 & 0.56 & 0.00 & 0.00 \\
$P(D, B)$ & 0.00 & 0.00 & 0.00 & 0.71 & 0.36 & 0.25 & 0.00 & 0.00 & 0.00 & 1.00 & 0.00 & 0.00 & 0.00 \\
$P(D, C)$ & 0.00 & 0.20 & 0.50 & 1.00 & 0.07 & 0.00 & 0.00 & 0.00 & 0.00 & 0.00 & 0.67 & 0.00 & 0.00 \\
\hline
\end{tabular}

$$
\left.\begin{array}{cccccc}
0 & 1 & 0 & 0.11 & 0.5 & 1 \\
0 & 0.2 & 0 & 1 & 1 & 0.29 \\
1 & 0 & 1 & 0 & 0.75 & 0.29 \\
0 & 0 & 1 & 0.67 & 0 & 0
\end{array}\right] .
$$

Step 4: Eq. 21 was used to determine the deviations between each of the two alternatives by pairwise comparisons. A summary of the deviations is presented in Table 5.

Step 5: Calculate the preference function using Eq. 22. Table 6 lists the deviations.

Step 6: Calculate the overall criteria weight, $w_{C}$, using the steps of Shannon entropy, and then multiply each column in the preference function matrix with its associated weight followed by adding each row in the weighted matrix to obtain the aggre- gated preference index as given in Eq. (23). The preference indices are presented in Table 7.

Step 7: Determine the positive outranking flow (leaving flow) and the negative outranking flow (entering flow) using Eqs. (24) and (25). The leaving flow and the entering flow of the alternatives are presented in Table 8.

Step 8: Calculate Euclidian distance from the ideal best solution, $S_{i}^{+}$, and the ideal worst solution, $S_{i}^{-}$, as shown in Table 9, based on the assumption that the positive ideal solution, $V_{j}^{+}$, and the negative ideal solution, $V_{j}^{-}$, in the TOPSIS method equal the leaving flow, $\phi^{+}$, and the enering flow, $\phi^{-}$, from PROMETHEE-II.

Step 9: Calculate the relative closeness coefficients of the 
Table 7. Preference index value

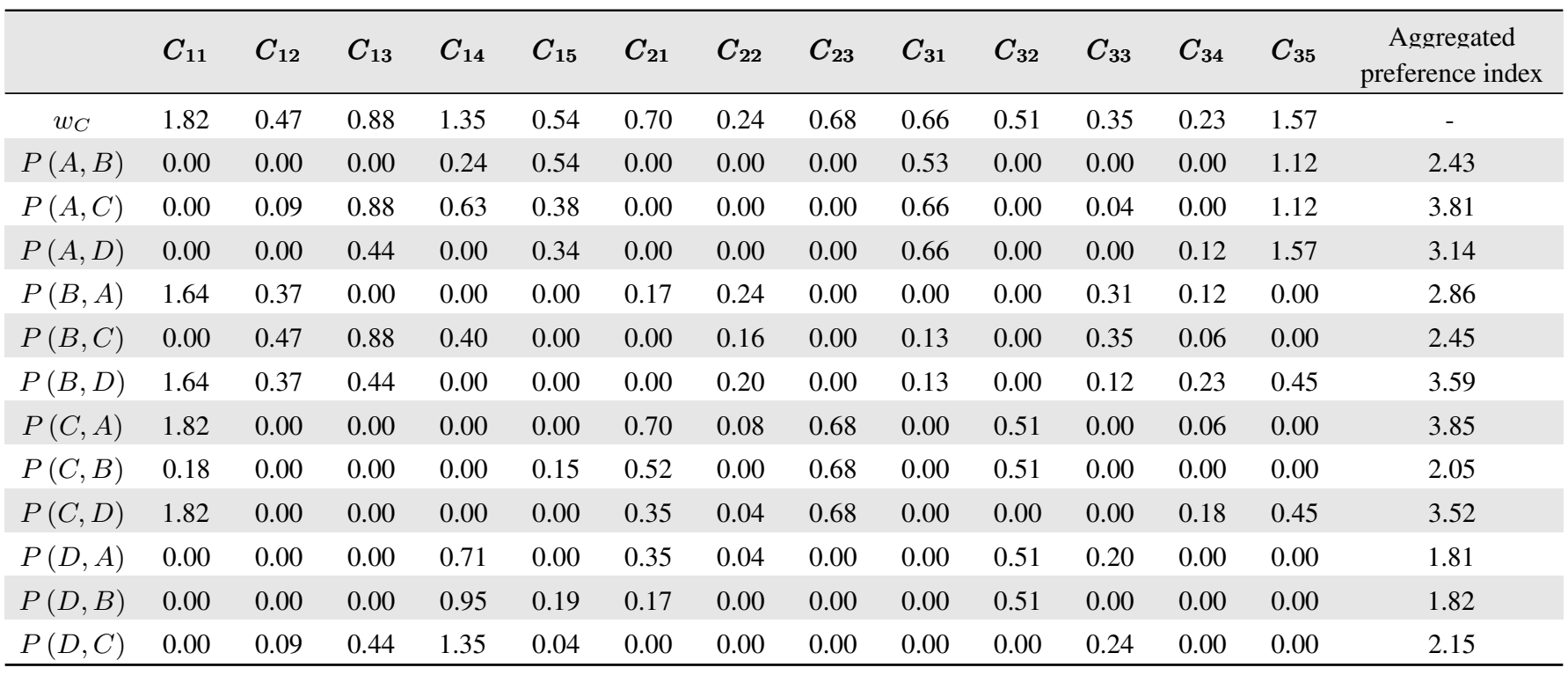

Table 8. PROMETHEE II flow

\begin{tabular}{cccccc}
\hline & A & B & C & D & $\phi^{+}$Leaving flow \\
\hline A & - & 1.86 & 4.26 & 2.35 & 2.83 \\
B & 2.86 & - & 3.46 & 3.36 & 3.23 \\
C & 3.85 & 2.05 & - & 3.07 & 2.99 \\
D & 1.81 & 1.82 & 2.94 & - & 2.19 \\
$\phi^{-}$Entering flow & 2.84 & 1.91 & 3.55 & 2.93 & - \\
\hline
\end{tabular}

Table 9. Positive and negative ideal solutions, $S_{i}^{+}, S_{i}^{-}$

\begin{tabular}{ccccccc}
\hline & A & B & C & D & $S_{\boldsymbol{i}}^{+}$ & $\boldsymbol{S}_{\boldsymbol{i}}^{-}$ \\
\hline A & - & 1.86 & 4.26 & 2.35 & 3.39 & 2.98 \\
B & 2.86 & - & 3.46 & 3.36 & 3.47 & 1.96 \\
C & 3.85 & 2.05 & - & 3.07 & 3.48 & 3.70 \\
D & 1.81 & 1.82 & 2.94 & - & 2.79 & 3.17 \\
$V_{j}^{+}$positive ideal & 2.83 & 3.23 & 2.99 & 2.19 & - & - \\
$V_{j}^{-}$negative ideal & 2.84 & 1.91 & 3.55 & 2.93 & - & - \\
\hline
\end{tabular}

Table 10. Rank of the alternatives based on the closeness coefficient

\begin{tabular}{ccccc}
\hline Alternatives & $\boldsymbol{S}_{\boldsymbol{i}}^{+}$ & $\boldsymbol{S}_{\boldsymbol{i}}^{-}$ & $\boldsymbol{P}_{\boldsymbol{i}}$ & $\begin{array}{c}\text { Alternatives } \\
\text { ranking }\end{array}$ \\
\hline A & 3.39 & 2.98 & 0.47 & 3 \\
B & 3.47 & 1.96 & 0.36 & 4 \\
C & 3.48 & 3.70 & 0.51 & 2 \\
D & 2.79 & 3.17 & 0.53 & 1 \\
\hline
\end{tabular}

ideal solution using Eq. (33). The ranking of the alternatives is presented in Table 10.

\section{Conclusions and Future Work}

The selection of alternative locations for the construction of wind power plants is typically a throne issue involving contradictory and unknown variables, and interactions between a variety of factors. The problem is generally overcome by a proper decision-making process.

We propose a hybrid MCDM approach with a combined weight method, which is based on the incorporation of NS theory, ANP, entropy, PROMETHEE II, and TOPSIS methods 
to select an appropriate location for the construction of a wind energy power plant in the Sinai Peninsula of Egypt.

The initial phase of the proposed hybrid MCDM method involved the elimination of all areas that were limited by valid constraints and credible reasoning. A detailed map of the region was created in the next phase based on the judgment of specialists and the combined SVNN-ANP method to simulate the uncertainty associated with vagueness in real-world environments. The next phase of the analysis was to separate the exclusion area from the defined area and to categorize the correct areas according to the weights they had achieved. In addition, entropy was used to calculate the combined weights of each criterion. The total weights were found to overcome the disparity between the subjective and objective weights, which helped to represent the main features of the decision-making problem and provide a more rational weight distribution. Ultimately, the PROMETHEE II and TOPSIS approaches allowed DMs to select the most suitable alternatives in the final decision. The results of the analysis indicate that the proposed hybrid MCDM approach can be implemented successfully for the selection of the most acceptable alternatives for wind power plant locations.

In future, the proposed hybrid method could be used to solve complex MCDM problems in other areas. In addition, the setting of the weight coefficient can be improved in future studies using an artificial intelligence algorithm. SVN numbers can be commonly used for more practical applications by modifying and generalizing the existing methods of rating fuzzy numbers and intuitionistic fuzzy numbers to achieve a more effective performance.

\section{Conflict of Interest}

No potential conflict of interest relevant to this article was reported.

\section{References}

[1] International Energy Agency. Key World Energy Statistics. Paris, France: International Energy Agency, 2007, pp. 364-373.

[2] C. A. C. Coello, G. B. Lamont, and D. A. Van Veldhuizen, Evolutionary Algorithms for Solving Multi-objective Problems. Boston, MA: Springer. 2007, pp. 313-324. https: //doi.org/10.1007/978-0-387-36797-2_6
[3] J. Malczewski and C. Rinner, Multicriteria Decision Analysis in Geographic Information Science. New York: Springer, 2015, pp. 231-252. https://doi.org/10.1007/9783-540-74757-4

[4] R. L. Church, "Geographical information systems and location science," Computers \& Operations Research, vol. 29, no. 6, pp. 541-562, 2002. https://doi.org/10.1016/ S0305-0548(99)00104-5

[5] D. Tong and A. T. Murray, "Spatial optimization in geography," Annals of the Association of American Geographers, vol. 102, no. 6, pp. 1290-1309, 2012. https: //doi.org/10.1080/00045608.2012.685044

[6] M. Rezaei-Shouroki, A. Mostafaeipour, and M. Qolipour, "Prioritizing of wind farm locations for hydrogen production: a case study," International Journal of Hydrogen Energy, vol. 42, no. 15, pp. 9500-9510, 2017. https://doi.org/10.1016/j.ijhydene.2017.02.072

[7] T. Kurka and D. Blackwood, "Selection of MCA methods to support decision making for renewable energy developments," Renewable and Sustainable Energy Reviews, vol. 27, pp. 225-233, 2013. https://doi.org/10.1016/j.rser.2013. 07.001

[8] B. Roy, "Paradigms and challenges," in Multiple Criteria Decision Analysis. New York, NY: Springer, 2016, pp. 19-39. https://doi.org/10.1007/978-1-4939-3094-4_2

[9] J. Watrobski and J. Jankowski, "Guideline for MCDA method selection in production management area," in New Frontiers in Information and Production Systems Modelling and Analysis. Cham, Switzerland: Springer, 2016, pp. 119-138. https://doi.org/10.1007/978-3-319-233383_6

[10] J. S. Dodgson, M. Spackman, A. Pearman, and L. D. Phillips, "Multi-criteria analysis: a manual," Department for Communities and Local Government, London, UK, 2009.

[11] J. Malczewski, GIS and Multicriteria Decision Analysis. New York, NJ: John Wiley \& Sons, 1999, pp. 292-301.

[12] V. Ferretti, "A multicriteria spatial decision support system development for siting a landfill in the province of Torino (Italy)," Journal of Multi?Criteria Decision Analysis, vol. 18, no. 5-6, pp. 231-252, 2011. https://doi.org/10.1002/ mcda.493 
[13] S. Leao, I. Bishop, and D. Evans, "Spatial-temporal model for demand and allocation of waste landfills in growing urban regions," Computers, Environment and Urban Systems, vol. 28, no. 4, pp. 353-385, 2004. https: //doi.org/10.1016/S0198-9715(03)00043-7

[14] Y. Chen, K. Takara, I. D. Cluckie, and F. H. de Smedt, GIS and Remote Sensing in Hydrology, Water Resources and Environment. Oxfordshire, UK: International Assn of Hydrological Sciences, 2004.

[15] W. Plata-Rocha, M. Gomez-Delgado, and J. BosqueSendra, "Simulating urban growth scenarios using GIS and multicriteria analysis techniques: a case study of the Madrid region, Spain," Environment and Planning B: Planning and Design, vol. 38, no. 6, pp. 1012-1031, 2011. https://doi.org/10.1068/b37061

[16] O. A. Omitaomu, B. R. Blevins, W. C. Jochem, G. T. Mays, R. Belles, S. W. Hadley, et al., "Adapting a GIS-based multicriteria decision analysis approach for evaluating new power generating sites," Applied Energy, vol. 96, pp. 292-301, 2012. https://doi.org/10.1016/j.apenergy.2011. 11.087

[17] A. Sultana and A. Kumar, "Ranking of biomass pellets by integration of economic, environmental and technical factors," Biomass and Bioenergy, vol. 39, pp. 344-355, 2012. https://doi.org/10.1016/j.biombioe.2012.01.027

[18] S. M. Baban and T. Parry, "Developing and applying a GIS-assisted approach to locating wind farms in the UK," Renewable Energy, vol. 24, no. 1, pp. 59-71, 2001. https: //doi.org/10.1016/S0960-1481(00)00169-5

[19] A. Bennui, P. Rattanamanee, U. Puetpaiboon, P. Phukpattaranont, and K. Chetpattananondh, "Site selection for large wind turbine using GIS," in Proceedings of the PSUUNS International Conference on Engineering and Environment, Hat Yai, Thailand, 2007, pp. 561-566.

[20] L. I. Tegou, H. Polatidis, and D. A. Haralambopoulos, "Wind turbines site selection on an isolated island," WIT Transactions on Ecology and the Environment, vol. 127, pp. 313-324, 2009. https://doi.org/10.2495/RAV090281

[21] K. B. Atici, A. B. Simsek, A. Ulucan, and M. U. Tosun, "A GIS-based multiple criteria decision analysis approach for wind power plant site selection," Utilities Policy, vol. 37, pp. 86-96, 2015. https://doi.org/10.1016/j.jup.2015.06.001
[22] Y. A. Solangi, Q. Tan, N. H. Mirjat, G. D. Valasai, M. W A. Khan, and M. Ikram, "An integrated Delphi-AHP and fuzzy TOPSIS approach toward ranking and selection of renewable energy resources in Pakistan," Processes, vol. 7, no. 2 , article no. 118,2019 . https://doi.org/10.3390/ pr7020118

[23] N. Jaini and S. Utyuzhnikov, "Trade?off ranking method for multi?criteria decision analysis," Journal of MultiCriteria Decision Analysis, vol. 24, no. 3-4, pp. 121-132, 2017. https://doi.org/10.1002/mcda.1600

[24] E. E. Karsak and M. Dursun, "An integrated fuzzy MCDM approach for supplier evaluation and selection," Computers \& Industrial Engineering, vol. 82, pp. 82-93, 2015. https://doi.org/10.1016/j.cie.2015.01.019

[25] N. Banaeian, H. Mobli, B. Fahimnia, I. E. Nielsen, and M. Omid, "Green supplier selection using fuzzy group decision making methods: a case study from the agri-food industry," Computers \& Operations Research, vol. 89, pp. 337-347, 2018. https://doi.org/10.1016/j.cor.2016.02.015

[26] N. Y. Aydin, E. Kentel, and S. Duzgun, "GIS-based environmental assessment of wind energy systems for spatial planning: a case study from Western Turkey," Renewable and Sustainable Energy Reviews, vol. 14, no. 1, pp. 364-373, 2010. https://doi.org/10.1016/j.rser.2009.07.023

[27] J. M. Ssnchez-Lozano, M. S. Garcia-Cascales, and M. T. Lamata, "GIS-based onshore wind farm site selection using fuzzy multi-criteria decision making methods: evaluating the case of Southeastern Spain," Applied Energy, vol. 171, pp. 86-102, 2016. https://doi.org/10.1016/j.apenergy. 2016.03 .030

[28] D. Latinopoulos and K. Kechagia, "A GIS-based multicriteria evaluation for wind farm site selection: a regional scale application in Greece," Renewable Energy, vol. 78, pp. 550-560, 2015. https://doi.org/10.1016/j.renene.2015. 01.041

[29] F. Smarandache, Neutrosophy: Neutrosophic Probability, Set, and Logic: Analytic Synthesis \& Synthetic Analysis. Rehoboth, NM: American Research Press, 1998.

[30] F. Smarandache, "Neutrosophic set: a generalization of the intuitionistic fuzzy set," Journal of Defense Resources Management, vol. 1, no. 1, pp. 107-116, 2010. 
[31] F. Smarandache, "Neutrosophic set is a generalization of intuitionistic fuzzy set, inconsistent intuitionistic fuzzy set (picture fuzzy set, ternary fuzzy set), pythagorean fuzzy set, spherical fuzzy set, and q-rung orthopair fuzzy set, while neutrosophication is a generalization of regret theory, grey system theory, and three-ways decision (revisited)," Journal of New Theory, vol. 2019, no. 29, pp. 1-31, 2019.

[32] H. Wang, F. Smarandache, R. Sunderraman, and Y. Q. Zhang, Interval Neutrosophic Sets and Logic: Theory and Applications in Computing. Pheonix, AZ: Hexis, 2005.

[33] H. Wang, F. Smarandache, Y. Zhang, and R. Sunderraman, "Single valued neutrosophic sets," 2010, Available: https://www.afahc.ro/ro/revista/NR_1_2010/Nr_1_ 2010.pdf\#page $=11$

[34] H. S. Hansen, "GIS-based multi-criteria analysis of wind farm development," in Proceedings of the 10th Scandinavian Research Conference on Geographical Information Science (ScanGIS), Stockholm, Sweden, 2005, pp. 75-87.

[35] H. Yousefi, H. Hafeznia, and A. Yousefi-Sahzabi, "Spatial site selection for solar power plants using a GIS-based Boolean-fuzzy logic model: a case study of Markazi Province, Iran," Energies, vol. 11, no. 7, article no. 1648, 2018. https://doi.org/10.3390/en11071648

[36] N. M. Radwan, M. B. Senousy, and M. R. Alaa El Din, "Neutrosophic AHP multi criteria decision making method applied on the selection of learning management system," International Journal of Advancements in Computing Technology, vol. 8, no. 5, pp. 95-105, 2016.

[37] 604167789T. L. Saaty and L. G. Vargas, "Sensitivity analysis in the analytic hierarchy process," in Decision Making with the Analytic Network Process. Boston, MA: Springer, 2013, pp. 345-360. https://doi.org/10.1007/978-1-46147279-7_15

[38] T. L. Saaty and L. G. Vargas, "The analytic network process," in Decision Making with the Analytic Network Process. Boston, MA: Springer, 2013, pp. 1-40. https://doi.org/10.1007/978-1-4614-7279-7_1

[39] S. H. Chung, A. H. Lee, and W. L. Pearn, "Analytic network process (ANP) approach for product mix planning in semiconductor fabricator," International Journal of
Production Economics, vol. 96, no. 1, pp. 15-36, 2005. https://doi.org/10.1016/j.ijpe.2004.02.006

[40] T. L. Saaty, The Analytic Hierarchy Process: Planning, Priority Setting, Resource Allocation. New York, NY: McGraw-Hill, 1980.

[41] C. E. Shannon, "A mathematical theory of communication," The Bell System Technical Journal, vol. 27, no. 3, pp. 379-423, 1948.

[42] J. P. Brans and P. Vincke, "Note-A Preference Ranking Organisation Method (The PROMETHEE Method for Multiple Criteria Decision-Making)," Management Science, vol. 31, no. 6, pp. 647-656, 1985. https://doi.org/10. $1287 / \mathrm{mnsc} .31 .6 .647$

[43] A. Albadvi, S. K. Chaharsooghi, and A. Esfahanipour, "Decision making in stock trading: an application of PROMETHEE," European Journal of Operational Research, vol. 177, no. 2, pp. 673-683, 2007. https://doi.org/ 10.1016/j.ejor.2005.11.022

[44] J. P. Brans, P. Vincke, and B. Mareschal, "How to select and how to rank projects: the PROMETHEE method," European Journal of Operational Research, vol. 24, no. 2, pp. 228-238, 1986. https://doi.org/10.1016/0377-2217(86) 90044-5

[45] C. L. Hwang and K. Yoon, "Methods for multiple attribute decision making," in Multiple Attribute Decision Making. Heidelberg, Germany: Springer, 1981, pp. 58-191. https: //doi.org/10.1007/978-3-642-48318-9_3

[46] H. A. Effat and O. A. Hassan, "Designing and evaluation of three alternatives highway routes using the Analytical Hierarchy Process and the least-cost path analysis, application in Sinai Peninsula, Egypt," The Egyptian Journal of Remote Sensing and Space Science, vol. 16, no. 2, pp. 141-151, 2013. https://doi.org/10.1016/j.ejrs.2013.08.001

[47] H. A. Effat and M. N. Hegazy, "A multidisciplinary approach to mapping potential urban development zones in Sinai Peninsula, Egypt using remote sensing and GIS," Journal of Geographic Information System, vol. 5, no. 6, article no. 41237, 2013. http://doi.org/10.4236/jgis.2013. 56054

[48] D. Pamucar, L. Gigovic, Z. Bajic, and M. Janosevic, "Location selection for wind farms using GIS multi-criteria 
hybrid model: an approach based on fuzzy and rough numbers," Sustainability, vol. 9, no. 8, article no. 1315, 2017. https://doi.org/10.3390/su9081315

[49] V. Gass, J. Schmidt, F. Strauss, and E. Schmid, "Assessing the economic wind power potential in Austria," Energy Policy, vol. 53, pp. 323-330, 2013. https://doi.org/10.1016/ j.enpol.2012.10.079

[50] Y. Noorollahi, H. Yousefi, and M. Mohammadi, "Multicriteria decision support system for wind farm site selection using GIS," Sustainable Energy Technologies and Assessments, vol. 13, pp. 38-50, 2016. https://doi.org/10. 1016/j.seta.2015.11.007

[51] R. Van Haaren and V. Fthenakis, "GIS-based wind farm site selection using spatial multi-criteria analysis (SMCA): evaluating the case for New York State," Renewable and Sustainable Energy Reviews, vol. 15, no. 7, pp. 3332-3340, 2011. https://doi.org/10.1016/j.rser.2011.04.010

[52] T. Hofer, Y. Sunak, H. Siddique, and R. Madlener, "Wind farm siting using a spatial Analytic Hierarchy Process approach: a case study of the Stadteregion Aachen," Applied Energy, vol. 163, pp. 222-243, 2016. https://doi.org/10. 1016/j.apenergy.2015.10.138

[53] D. G. Vagiona and M. Kamilakis, "Sustainable site selection for offshore wind farms in the South AegeanGreece," Sustainability, vol. 10, no. 3, article no. 749, 2018. https://doi.org/10.3390/su10030749

[54] E. B. Arnett, D. B. Inkley, D. H. Johnson, R. P. Larkin, S. Manes, A. M. Manville, R. Mason, M. Morrison, M. D. Stricckland, and R. Thresher, "Impacts of wind energy facilities on wildlife and wildlife habitat," Wildlife Society, Technical Review 07-2, 2007.

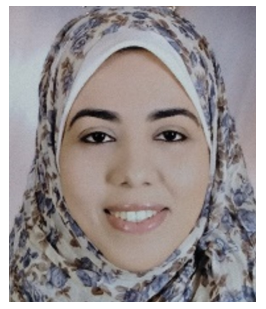

Amany Mohamed Elhoainy is a $\mathrm{PhD}$ candidate at Faculty of Computers and Information Sciences, Mansoura University, Egypt. She is a lecturer assistant at Information System Department, Sadat Academy for Management Sciences, Tanta, Egypt. Her research work focuses on geographical information systems, remote sensing, intelligent information system, and neutrosophic set theory.

E-mail: amanyelhosiny2020@gmail.com

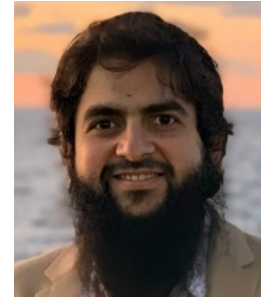

Haitham El-Ghareeb is an associate professor of Information Systems at Faculty of Computers and Information Sciences, Mansoura University, Egypt. He is a member of many distinguished computer organizations, reviewer for different highly recognized academic journals, contributor to open-source projects, and the author of different international published books. Haitham is interested in ERP systems, intelligent information systems, and systems integration.

E-mail:

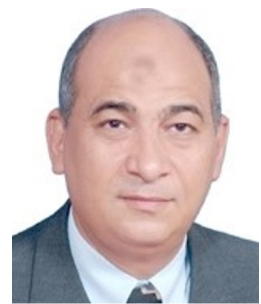

Bahaa T. Shabana is an associate professor, was born in Mansoura, Egypt, 1963; received the B.Sc. degree in Mathematics from Faculty of Sciences, Mansoura University in 1986. He received higher diplomas in Education, 1988; Pure Mathematics and Scientific Computations, 1999; and Statistics and Computer Sciences, 2001; from Mansoura University, Egypt. $\mathrm{He}$ also received a higher diploma of Computer Science and Information Systems, 2003; M.Sc. of Computer and Information System, 2008; from Institute of Statistical Studies and Researches (ISSR). He received Ph.D. of Statistics and Computer Science, 2012, from Faculty of Science, Mansoura University, Egypt. He is interested in geographic information systems (GIS), GIS applications digital photogrammetry, and road networking.

E-mail:

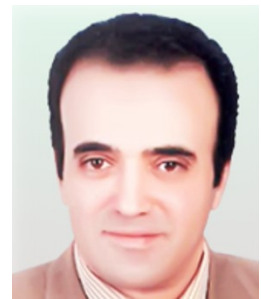

Ahmed AbouElfetouh he is professor at Information system Department, Mansoura University, Egypt. He received Prof Degree in Information system Department from Faculty of Computers and Information Mansoura University, Egypt, in 2013 He is Vice Dean for Graduate Studies and Research in Egypt from 2013.

E-mail: 